\title{
Lean Six Sigma for the improvement of company processes: the Schnell S.p.A. case study
}

\section{Federica Murmura and Laura Bravi}

Department of Economics, Society, Politics, Università Degli Studi di Urbino Carlo Bo, Urbino, Italy

Fabio Musso

Department of Economics, Society and Politics, University of Urbino Carlo Bo, Urbino, Italy, and

Aleksandra Mosciszko

Department of Economics, Society, Politics, Università Degli Studi di Urbino Carlo Bo, Urbino, Italy

\begin{abstract}
Purpose - The aim of this study is to develop an in-depth case study on the implementation on Lean six sigma (LSS) in Schnell S.p.A., Italian company leader of an important multinational industrial group, highlighting the benefits that can be achieved from a careful application of this method, the main challenges and organizational learning from its implementation.

Design/methodology/approach - The study has been developed with a qualitative approach, creating a single in-depth case study, with the participant observation of researchers in the project which lasted 4 months. Periodic weekly meetings were done with the working group to exchange feedback on the development of the project to share opinions and data.

Findings - A project has been developed to stabilize the procurement process of a pull-type production cell, which experienced delays in supply lead times. The causes of the problems in their process of managing the supply of the production cell were found and some inefficiencies in the internal process of fulfillment of supply orders have been intercepted, the optimization of which has allowed the generation of an automatic system for sending supply orders, coming directly from the production line.

Originality/value - This study described the path and dynamics of the transformation process that business organizations undertake for optimizing their profitability and competitive advantage, placing emphasis on an innovative methodology for conducting business process improvement projects, which constitutes its operating philosophy on the effective and efficient use of company resources and skills, to guarantee to the company the achievement of a lasting and defensible competitive advantage over time.
\end{abstract}

Keywords Lean thinking, Lean production, Quality management, Continuous improvement

Paper type Case study

\section{Introduction}

The development of an effective quality improvement or continuous improvement strategy is a key factor for long-term success of modern organizations. Over the last decade, Lean Six

(C) Federica Murmura, Laura Bravi, Fabio Musso and Aleksandra Mosciszko. Published by Emerald Publishing Limited. This article is published under the Creative Commons Attribution (CC BY 4.0) licence. Anyone may reproduce, distribute, translate and create derivative works of this article (for both commercial and non-commercial purposes), subject to full attribution to the original publication and authors. The full terms of this licence may be seen at http://creativecommons.org/licences/by/4.0/legalcode

The authors acknowledge Schnell S.p.A. for supporting the research providing the data that allowed the realization of the case study.
Received 30 June 2021 
TQM

33,7

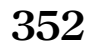

Sigma (LSS) has become one of the most popular and proven business process improvement methodologies organizations have ever witnessed in the past (Antony et al., 2017), and it has been accepted globally as a management strategy for achieving Process Excellence (Gijo et al., 2019).

Lean Six Sigma is a management strategy for improving corporate productivity and profitability, that aim to maximize the Customer satisfaction by reducing constraints which the company organization is subject in terms of activities that do not create value for the Customer. In practice, LSS is an improvement strategy that analyze quantitative data on business performance to identify, eliminate and control problems and inefficiencies related to manufacturing cost, service cost, quality, productivity and customer satisfaction (Singh and Rathi, 2019; Snee, 2010) throughout the business processes.

The objectives of quality and efficiency, supported by Lean Six Sigma, are made by DMAIC: a structured method for improving the performance of existing processes (Sordan et al., 2020), based on the application of the concepts Define, Measure, Analyze, Improve and Control. It provides a standardized guideline for the elaboration of improvement projects and provides different statistical tools and techniques appropriate to each phase of the DMAIC cycle (Sordan et al., 2020) able to lead to the root causes of business problems and to eliminate the wastes and reduce the variation, thus, ensuring substantial improvement in business processes (Bhat et al., 2020).

The term LSS was first introduced into literature around 2000 LSS, while LSS teaching was established in 2003 as part of the evolution of Six Sigma (Timans et al., 2012). Since that time, there has been a noticeable increase in LSS popularity and deployment in the industrial world (Shah et al.,2008) and researchers had the interest to publish more papers on LSS to try to come up with a comprehensive approach to achieve continuous improvement. However, as suggested by Albliwi et al. (2015), there are still many gaps that need to be addressed in LSS literature such as benefits, motivation factors, challenges and limitations (Pepper and Spedding, 2010; Laureani and Antony, 2012), and there is also a lack of research in the relation between LSS and organizational learning and in recent years a lot of systematic literature reviews on the topic have been published on the topic but only few case studies have been analyzed in the research field to cover this gap.

Therefore, the aim of this study is to cover this gap, by developing an in-depth case study on the implementation on LSS in an Italian company leader of an important multinational industrial group, that is Schnell S.p.A., that constitutes its main research and production center and provides technological, organizational and commercial support for the entire group. Schnell operates in over 150 countries around the world through its 11 subsidiaries, over 50 agents and resellers, and a dense network of service centers.

This research work has the objective of highlighting the benefits that can be achieved from a careful application of LSS method in the company, the main challenges and also organizational learning from LSS implementation, showing its application in details in an important reality like that of Schnell S.p.A.

The paper is structured as follows: Section 2 depicts the theoretical background, describing the merging of Lean Production and Six Sigma and defining the critical success factors of lean six sigma implementation; Section 3 defines the methodology used, Section 4 presents and discusses the results of the case study while the last section draws the main conclusions.

\section{Literature review}

\subsection{The merging of two quality philosophies: Lean production and Six Sigma}

The LSS notion was announced to the world in 2002, when Michael George used it for the first time in the book "Lean Six Sigma: Combining Six Sigma with Lean Speed" (Sordan et al., 2020; Sreedharan and Raju, 2016). He is the founder and Chief Executive Officer of the George Group, one of the largest LSS project consulting firms in the United States. 
Although its appearance is quite recent, LSS arise from two complementary but different approaches (Sordan et al., 2020): Toyota Production System (TPS), a famous organizational orientation developed in Japan, from the 1960s and 1980s, spread with the concept of "Lean Thinking"; and Six Sigma, a technical quality management program, introduced by Motorola Corporation in manufacturing arena in 1987 (Singh and Rathi, 2019).

The synergy between Lean and Six Sigma created a data-driven (Sreedharan and Raju, 2016) and top-down business strategy to improve the quality and productivity of organizations (Singh and Rathi, 2019; Sordan et al., 2020).

When we talk about Lean Thinking, we are talking about a business culture, based on respect, trust and cooperation between employees and oriented by a constant search for perfection that allows to reach the highest quality of products and services offered by the company and consequently to maximize customer satisfaction.

To achieve this goal of perfection and to optimize profits, corporate actions must be aimed at a constant effort to reduce costs and wastes of tangible and intangible resources, by distinguishing valued-added activities from non-value-added activities and eliminating wastes that increases cost without adding value in the eyes of the customer (Antony et al., 2017; Cudney et al., 2014): activities that are unnecessary and not required for the operations of the business (Jayaram, 2016).

Lean Thinking emphasizes on productivity improvement along with speed to respond to customer needs and create a streamlined, high-quality system that produces finished products at the pace of customer demand with little or no waste (Lande et al., 2016).

Wastes are called Muda, and they can be defined as real sins that hinder the ideals of perfection. The eight types of waste are defined as transport, inventory, motion, waiting, overproduction, overprocessing, defects and non-utilized skills (Gijo et al., 2019). To identify and eliminate Muda, Lean strategy brings a set of proven tools and techniques that allow to reduce lead times, inventories, set up times, equipment downtime, scrap, rework and other wastes of the hidden factory (Lande et al., 2016). Corbett (2011) affirms that while lean focuses on the elimination of waste and improving flow, it has some secondary effects: quality is improved; the product spends less time in the process, thereby reducing the chances of damage and obsolescence.

But we have to remember that the commitment to Lean Thinking must start at the top management level and should be cascaded down to various levels across the organization to improve flow and efficiency of processes (Antony et al., 2017).

Six Sigma (SS) is a business process improvement and problem-solving approach (Lande et al.,2016) that seeks to find and eliminate causes of variability, as well as defects or mistakes in business processes, by focusing on process outputs which are critical in the eyes of customers (Antony et al., 2017). The main objective of Six Sigma is to obtain "zero defect" or, in statistical terms, to reduce defects up to 3.4 parts per million opportunities (Singh et al., 2019).

To study variability, Six Sigma utilizes a problem-solving methodology to define, measure, analyze, improve and control processes and implement cost-effective solutions leading to significant financial savings (Singh et al., 2019) not only for manufacture sectors but also remove the defects throughout the corporations (Singh and Rathi, 2019). This methodology is called DMAIC and it emphasizes on variation reduction, defect reduction and process evaluation (the effectiveness issue).

The complementarity between both approaches can be justified when the deficiencies inherent in each of them are observed, acting in isolation (Sordan et al., 2020). Both had produced tremendous results but had limitations: Lean is not well suited to resolving complex problems that require intensive data analysis, and advanced statistical methods, and, Six Sigma implementation showed how not every problem can be resolved with only a big data collection (Antony et al., 2017). 
TQM

33,7

Lean does not address variation within a process; rather it addresses variation between end-to-end processes which appears in the form of waste. One of the major limitations of Lean is that it cannot be used to tackle problems related to process stability and capability (Gijo et al., 2019) and it tends to work best with "solution known" problems, where we realize that we are not operating to best practices, Lean implements them and make rapid improvements with minimal data collection (Hoerl and Gardner, 2010). Six Sigma is most effective when used for improvement projects intended to drive processes towards process entitlement, in situations where the solution to the problem is unknown (Snee and Hoerl, 2007).

As stated by Pepper and Spedding (2010) if lean is implemented without Six Sigma, there is a lack of tools to fully exploit the improvement of its potential. Conversely, if Six Sigma is adopted without lean thinking, there would be a cache of tools for the improvement team to use, but no strategy or framework to bring one's application to a system.

Combining Lean manufacturing principles and Six Sigma tools and techniques enables organizations to form a powerful improvement combination (Hoerl and Gardner, 2010; Lande et al., 2016) that has allowed many organizations to solve more problems quicker (Antony et al., 2017). It is a successful integration because Lean focuses on improving the flow of information and materials between the steps in the process and Six Sigma works to improve the value-adding transformations which occur with in the process steps (Antony et al., 2017).

LSS defines an approach, but of course does not dictate the specific progression of the project or dictate the unique mix of tools to be used, which of course needs to be problem specific (Hoerl and Gardner, 2010). The appropriate blend of Lean and Six Sigma tools useful on any one problem therefore depends on the nature of the specific problem being solved (Antony et al., 2017).

The marriage between these two methodologies provides a more integrated, coherent and holistic approach to continuous improvement (Pepper and Spedding, 2010) and has led to the creation of a breakthrough managerial concept (Sordan et al., 2020; Chiarini, 2012) with the aim to create a new business culture that breaks the link with the traditional way of working in all productive functions. LSS adds a new task to daily working duties: the recovery of operational efficiency through training growth of people, extensive use of data culture and problem-solving methodologies; all activities that simultaneously allow the improvement of quality, the costs and business complexities reduction, the increasing revenue (Galdino de Freitas and Gomes Costa, 2017; Jayaram, 2016) and, finally, greater reliability of the services provided to the end customer. The application of LSS methodology results in reduced waste, defects and improve process, which in turn provide high-quality products at minimum cost, and this leads to customer delight, which ultimately raises the societal living standard (Singh et al., 2019; Jayaram, 2016), the well-being of employees and the quality of the work environment (Galdino de Freitas and Gomes Costa, 2017).

LSS aims not only to improve financial results through the improvement of company production processes, but it targets to help organizations build an adequate relationship with society, employees and the environment (Galdino de Freitas and Gomes Costa, 2017).

Both Lean and SS require a company to focus on its products and customers and LSS as a part of management strategy to increase the market share and maximize profit (Lande $e$ t al., 2016). It produces benefits in terms of better operational efficiency, cost-effectiveness and higher process quality, because it promotes total employee participation from both top-down and bottom-up as a win-win practice to both management and staff members (Gijo et al., 2019).

\subsection{Critical success factors of lean six sigma implementation}

Lean Six Sigma strategy is versatile in nature and has a lot of applications in a variety of industries. 
It can be applied in manufacturing as well as non-manufacturing environment (Singh and Rathi, 2019). It has broad applicability in service, healthcare, government, non-profits, education (Antony et al., 2017) automotive, textile, steel and aerospace industries (Sordan et al., 2020). Although LSS has its roots in manufacturing, it is proven to be a well-established process excellence methodology in almost every sector despite its size and nature (Gijo et al., 2019). It is useful in small-and medium-size organizations as well as large organizations (Antony et al., 2017).

LSS is also suitable for less experienced organizations: Bhat et al. (2020) write about the successful deployment of LSS strategy in an Indian industry with orthodox industrial practices, limited manpower, constrained capital and confined knowledge on scientific improvement practices, and the research proves that even a novice user can effectively participate and implement LSS with proper mentoring to enhance the system.

Regardless of the sector in which the LSS is applied, this shows the spread of LSS in various organizations as one of the best strategies for organizational excellence (Sreedharan and Raju, 2016). But it is important to remember that achieving maximum strategic and management efficiency cannot be based on the replication of principles and models of Lean approach.

Each organization is immersed in different social, cultural and economic conditions. For this reason, lean tools must be sized and customized on business contexts and simultaneously the entire business organization must be adapted to the changes that Lean Six Sigma generates and that it needs to be applied effectively (Lande et al., 2016; Raval et al., 2018; Singh et al., 2019; Gijo et al., 2019).

These requirements for cultural change are the main critical success factors for LSS (Sreedharan and Raju, 2016).

Critical success factors are the actions and processes that must be controlled by the management (Lande et al., 2016) during the implementation of a LSS project.

What contributes to the success of a LSS project is referable to the following:

(1) Top management involvement and commitment (Lande et al., 2016; Gijo et al., 2019). The top management involvement and commitment are essential for successful implementation (Pepper and Spedding, 2010) of any LSS initiative. It must personally support all improvement initiatives and integrate the LSS culture into entire organizations. Its active participation can multiply the positive project effects and make a significant impact at all levels (Gijo et al., 2019). If the top management will not take initiatives and not show their full involvement it could cause the failure of LSS implementation (Singh et al., 2019).

(2) Employee involvement, empowerment and training (Lande et al., 2016; Gijo et al., 2019; Bhat et al., 2020). The cultural growth of internal staff is the heart of LSS programs because it offers necessary tools to create a clear vision of the project, to focus on teamwork and, above all, to fight the resistance to cultural and operational changes (Singh et al., 2019; Sunder and Antony, 2018). Employee training also contributes to gain a high level of internal communication which facilitates the implementation of LSS (Lande et al., 2016; Singh et al., 2019; Gijo et al., 2019; Bhat et al., 2020). Training is necessary to create a supporting infrastructure (the belt system) and a holistic approach to improvement including area of application and methodology used (Antony et al., 2017). The belt system includes Master Black Belt, Black Belt, Green Belt, Yellow Belt and depending on the complexity of the problem considered and skills required to solve it, the appropriate Belts are selected (Gijo et al., 2019) to play the role of leadership and guidance of the project team.

(3) Linking LSS to business strategy and customer satisfaction (Lande et al., 2016). Improvement projects must be closely linked with maximizing customer satisfaction. 
TQM

33,7

\section{6}

Top management defines business objectives and identifies improvement projects capable of guaranteeing greater remuneration in terms of optimizing company productivity and profitability, as well as projects that can be reached using available resources, which do not require high investments and which allow to obtain undisputed results with limited deadlines in a limited period of time. Improper linkage between organizational objective and customer's requirement leads to failure of LSS implementation (Singh et al., 2019; Singh et al., 2019; Gijo et al., 2019).

\section{Methodology}

The study is a conceptual development and it has been developed with a qualitative approach, creating a single in-depth case study of Schnell S.p.A. that derives from a Group Purchasing Excellence Project. The case study allowed for examining in depth the implementation of a Lean Six Sigma improvement project for the transformation and simplification of the production process of the Schnell "Alfa" and "Beta" machines with the aim to reduce the delivery times of its products (Yin, 1994). The case study was developed with the participant observation of researchers in the project which lasted 4 months, starting from November 4, 2019 to March 4, 2020. As for the participant observation, the researcher was directly involved in the LSS implementation activities, collaborating with the working group in the figure of the project manager, and facing directly obstacles and problems that emerged during these stages of the same (par. 4.2.1.1 will define the detailed description of the project). Periodic weekly meetings were done with the entire working group to exchange feedback on the development of the project, to share opinions and data. Participant observation activity was triangulated with secondary data, such as company reports and the website, collected during the period of support in the company. Secondary data have been used mostly to describe Schnell history, structure and the services it offers to customers.

Minitab 19 statistical analysis software was used to describe and summarize the data collected during the project and shown in the result section.

\section{Results and discussion}

\subsection{Company profile: Schnell S.p.A}

Schnell S.p.A. is an Italian company that has been operating for almost 60 years in the manufacturing sector of automatic machines and plants for processing iron for reinforced concrete. It was born in 1962 thanks to the devotion of a group of entrepreneurs, driven by the dream of transforming the tiring and dirty world of iron working, into a modern industry, dedicated to conquering the global market. The company embarks on its own path by offering a first innovative solution that allowed faster binding of the reinforcing bars, flanked by the production of construction site machinery for cutting and bending the bars. The rise in the automatic machinery sector has started with the development of mechanisms for the production of cylindrical cages; however, the real change of course compared to its competitors will take place with the addition of electric servomotors, used, before now, only in fields such as robotics and military industry. Thanks to this type of instrumentation, Schnell machines are characterized by high power, speed, reliability and precision. They guarantee to the customer the achievement of economies of scale and better production techniques due to the high productivity offered, reduced set up times and low maintenance costs. Schnell S.p.A. offers the market a high range of machines and systems that allow a variety of processing of iron for reinforced concrete, including straightening, stirrup bending and shaping machines for bending, shaping and cutting iron in rolls or bars; cage making machines for the formation of cylindrical poles and cages for construction; machines and plants for the production of electrowelded mesh; machines for wire straightening and cold rolling lines; rotor straightening machines for processing steel wires for the industrial sector; machines for 
the production of prefabricated insulating panels for building construction; software for the management of iron processing centers using Schnell automatic machines. As a result of the high quality of these products, Schnell S.p.A. has managed to win the trust of its customers all over the world, reaching a turnover of over 100 million euros.

The Schnell Group is characterized by a staff of over 700 employees worldwide, and is made up of 5 production plants; 7 centers for installation, sales, spare parts and after-sales services; Schnell Software (Spain), which is a center for the creation and development of software systems for the management and organization of production carried out using Schnell machines and Schnell Home S.r.l., production center of machines for the construction of innovative elements for building construction, called "Concrewall". Achieving a highly competitive advantage over its competitors in the same sector was possible due to constant investments in research, development and technological innovation of products and processes. Product innovation, since the company is always ready to respond to market needs through the development of a customer-oriented approach, which allows to offer integrated and customized production solutions. Process innovation, since, as stated in the "Integrated Quality Policy" and "Purchasing Excellence Group Program" of Schnell S.p.A., the efforts of the whole company are oriented to create effective methods of managing internal operational processes, with a view to maximizing end customer satisfaction.

As a result of the constant commitment in this direction, at the end of 2007, Schnell S.p.A. managed to obtain the quality system certification according to the ISO 9001 standard, delivered by the prestigious certification body TUV Italy, and renewed in 2019 in compliance with the updates undergone by the standard in September 2015.

The important results obtained in terms of product and process quality was also possible due to the dissemination and application of Lean Manufacturing principles and methodologies.

\subsection{The development of the lean six sigma project in Schnell S.p.A}

At the end of 2017, for the continuous maximization of the efficiency of response to market needs, Schnell S.p.A. has embarked on the path of reducing delivery times for its products. To this end, an improvement project was launched for the transformation and simplification of the production process of the Schnell "Alfa" and "Beta" machines. Until then, the phases for the realization of Schnell products took place entirely in the company's internal plants; among others, the production process included the assembly phases of the single components and sub-assemblies, foreseen for the creation of the bill of materials of the machines. At the level of procurement and planning, this type of production involved the governance of a large amount of codes for raw materials and semi-finished products. As a result, the production was characterized by long productive Takt Times and involved high capital costs. For the realization of the pilot project, a particular production cell was conceived, completely autonomous, called the In-Lining Line, designed and built on the basis of Lean principles. The following transformations were carried out inside:

(1) The layout of the cell, the equipment and the production tools have been designed and arranged horizontally following the phases of the process;

(2) The production plans were planned on order, therefore, on the basis of the orders received from its customers, following the production theories with the pull logic;

(3) The manufacturing of the machines was organized in small batches conducted with the one-piece flow system;

(4) The management of the entire procurement process of raw materials and production components has been entrusted to the Kanban system; 
TQM

33,7

358
(5) The line operators have been trained to complete all manufacturing operations in complete autonomy.

To simplify and speed up the production process, strategic "make or buy" levers were used: the assembly phases of the basic production components for the construction of the machines were assigned to strategic Business Partners with whom Schnell had intense collaborative relationships built over the years. These have been regulated through the stipulation of specific subcontracting contracts, which, among the various agreed conditions, specify the following:

(1) The products supplied with their own identification codes;

(2) Periodicity of reordering;

(3) Minimum order quantity;

(4) Delivery Lead Time (in working days);

(5) Safety Stock Level: quantity of products to be held in the warehouse as a mandatory stock;

(6) Technical specifications of production;

(7) Specifications for packaging and delivery.

For further stabilization of the production process, aimed at increasing product quality, the characterizing element of the In-Lining Line was to reach a Free-Pass quality level. This qualitative incoming methodology has allowed a high reduction in the variability of the external production process, of the components characterized therein, while requiring significant direct and indirect investments by sourcing.

The entire In-Lining apparatus is governed by a vital element for the correct planning of the production phases: the supply Lead Time.

This index represents the time elapsing from the time of issue of the purchase order to the time of actual receipt of the goods. It allows to efficiently plan the supply of production components, and therefore, to define the periods for sending purchase orders.

Considering the high importance assumed in terms of evaluating the performance of its suppliers, the supply Lead Time analysis was included among the "continuous improvement" activities of the Purchasing excellence manual of Schnell S.p.A., and a monitoring system was activated on the performance of its suppliers, indexing two elementary groups of Key Performance Indicators:

(1) Lead time of supply;

(2) On-time Delivery (the ratio between the number of orders processed on time and the number of total orders processed, in the period considered).

With a view to Project Management, a work team was set up with the task of studying and analyzing the procurement process of the In-Lining line, and the phases of the Plan-Do-CheckAct (PDCA) and DMAIC approach were followed for the implementation of the project.

4.2.1 "Define" phase. The objective of the first phase of the project was to identify all the aspects necessary to define the process to be improved, therefore, to develop a planning prospectus called Project Charter containing: the representation of the problem detected, the objectives to be achieved, the requirements required from the customer, the inputs and outputs of the process and the metrics necessary to measure it, the enhancement of the current process and possible savings achievable by improving the process, the team members, and finally, the deadlines of the project phases. 
4.2.1.1 Project description. Analyzing the lead times of supply of the supplying process of the In-Lining Line, conducted with the Kanban system, it was reported that the most important supplier in terms of quantity, tends not to respect the agreed delivery terms.

Within the agreements, the primary requirements allow for a delivery lead time of 5 working days. Based on these parameters, the Critical to Quality (CTQ) requirements have been defined in terms of process specification limits, that is, the lead time interval within which deliveries can be made:

(1) Upper specification limit (USL) = LEAD TIME 5 days (working);

(2) Lower specification limit (LSL) = LEAD TIME 2 days (working).

Subsequently, the team has set itself the goal of:

(1) Analyze the deliveries to the line of the last available calendar period, from 01/11/2018 to $31 / 10 / 2019$;

(2) Perform stratification of the detected deliveries, until the root causes are reached;

(3) Define the initiatives and control charts to ensure the stability of the procurement process over time.

The main metrics used to evaluate the performance achieved were:

(1) Lead Time of supply;

(2) Defects per Unit - DPU;

(3) Defects Per Million of Opportunity - DPMO;

(4) Sigma Level.

The project team was made up of the members defined in Table 1.

The implementation of the DMAIC phases was organized through the Gantt Chart (Figure 1), with the aim of a precise subdivision over time of the individual activities to be carried out, while all the information that defines the project was collected in the Project Charter document of Figure 2.

4.2.1.2 Project risk analysis. During the planning of the project, different potential risks were identified that could affect the smooth running of the project. These were found in relation to different sources from which they could derive (see Table 2).

The analysis and assessment of the hypothesized risks was carried out on the basis of three variables:

(1) Severity (P): expresses the potential damage that the occurrence of the risk could cause in the implementation of the project;

(2) Occurrence $(\mathrm{G})$ : expresses the probability that the risk may occur;

(3) Detection (R): expresses the probability of risk detection once it has occurred.

\begin{tabular}{ll}
\hline Figure & Business department \\
\hline Head of purchase department & Purchase department \\
Project manager & External advisor \\
Strategic buyer metal parts & Purchase department \\
Design to cost manager & Purchase department \\
Back office & Purchase department \\
Production planner & Production department \\
ICT manager & Information technology department
\end{tabular}

Lean six sigma for company processes 


\section{TQM}

33,7

360

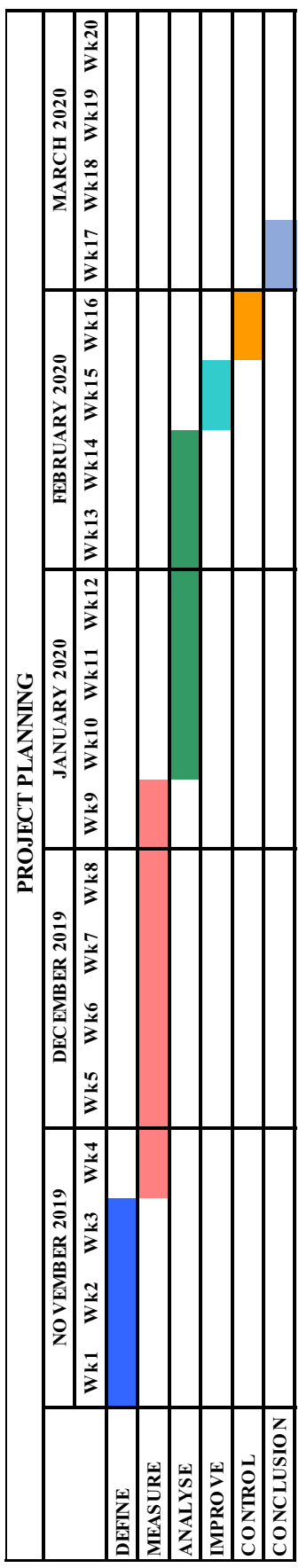

Figure 1 . 


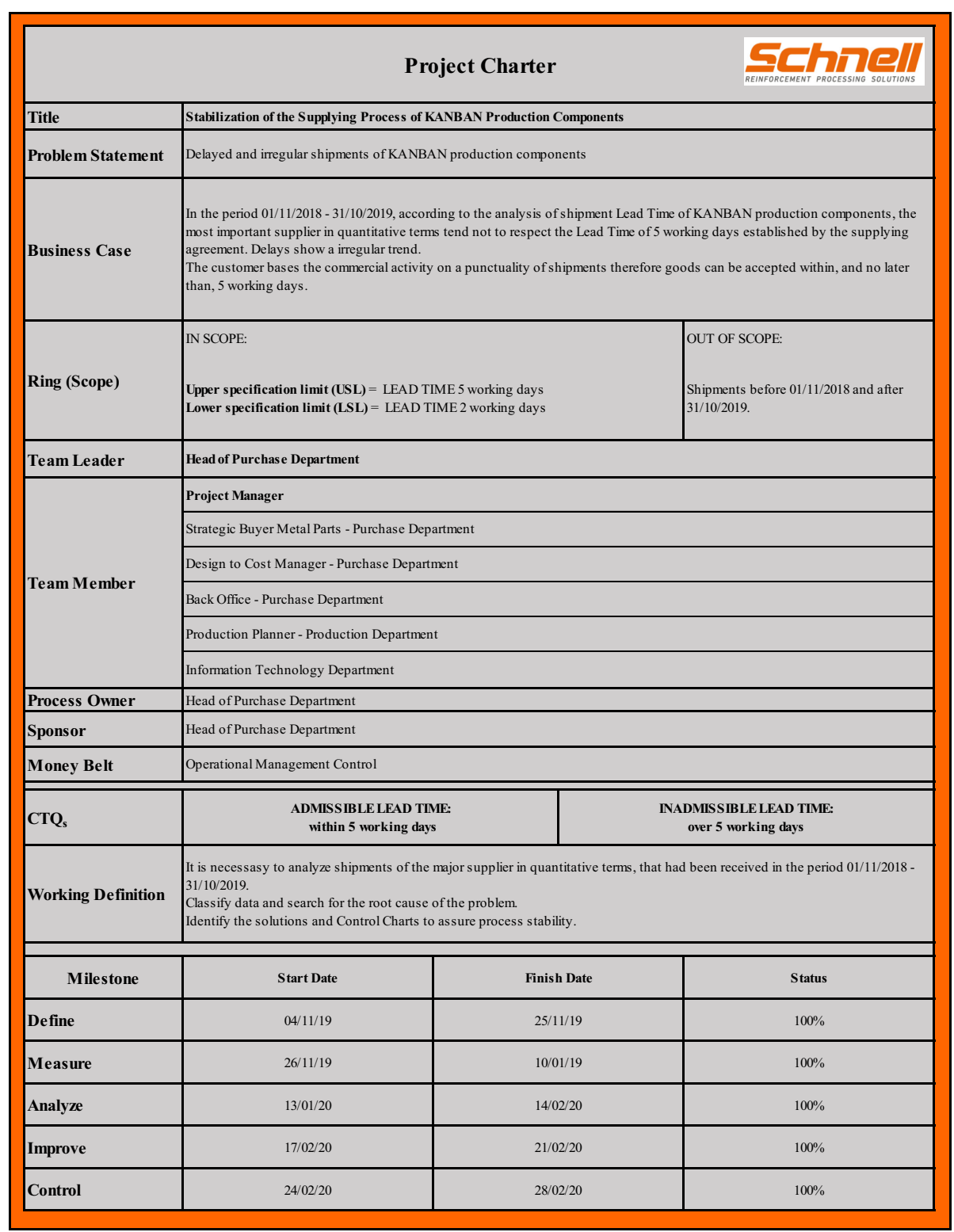

\section{Lean six sigma for company processes}

Figure 2. Project charter

Each variable was assigned a score from 1 to 5 , in which 1 represents an insignificant risk condition and 5 that of extreme risk (only for the Detection variable, the lower the score assigned, the greater the probability of risk detection).

The most critical risks have been identified through the Risk Priority Index - Risk Priority Number (RPN) obtained from formula f.1. 
TQM

33,7

\section{Risk area}

A. Technologies and resources

B. Timing

\section{2}

C. Customers

Table 2.

Project risk analysis
Type of specific risk

(A1) Unavailability of resources

(A2) Inaccessibility to tools and materials

(A3) Inability to use software

(B1) delays in the provision of information

(B2) variation of the project phases

(C1) change in project requirements

(C2) change in specification limits

(D1) Interruption of project funding

(E1) poor participation and seriousness of the members

(E2) Insufficient knowledge and skills of members

$$
f .1) \mathrm{RPN}=S \times O \times D
$$

The highest priority was checked for the risks "Inability to use software" and "Insufficient knowledge and skills of members" (see Table 3).

4.2.1.3 Process representation. To obtain a macro view of the process, the Supplier Input Process Output Customer (SIPOC) diagram has been developed (Figure 3) which highlights the main elements that make up the activities examined.

4.2.2 "Measure" phase. The second phase was aimed at defining and measuring the progress of the process at the current stage. For a better representation, the flow of activities necessary to replenish the In-Lining line has been outlined through the Flow Chart (Figure 4) which identifies on the left side the operations that add value within the process (AV), while, on the right side, those with non-added value (NAV), therefore considered as waste.

The process was further represented through the Value Stream Mapping technique (Figure 5) which allowed to estimate a total Process Time (P/T) of $11.6202 \mathrm{~h} \mathrm{(11} \mathrm{h} 37$ min and $12 \mathrm{~s})$,

Table 3.

Project risk and calculation of the Risk Priority Index

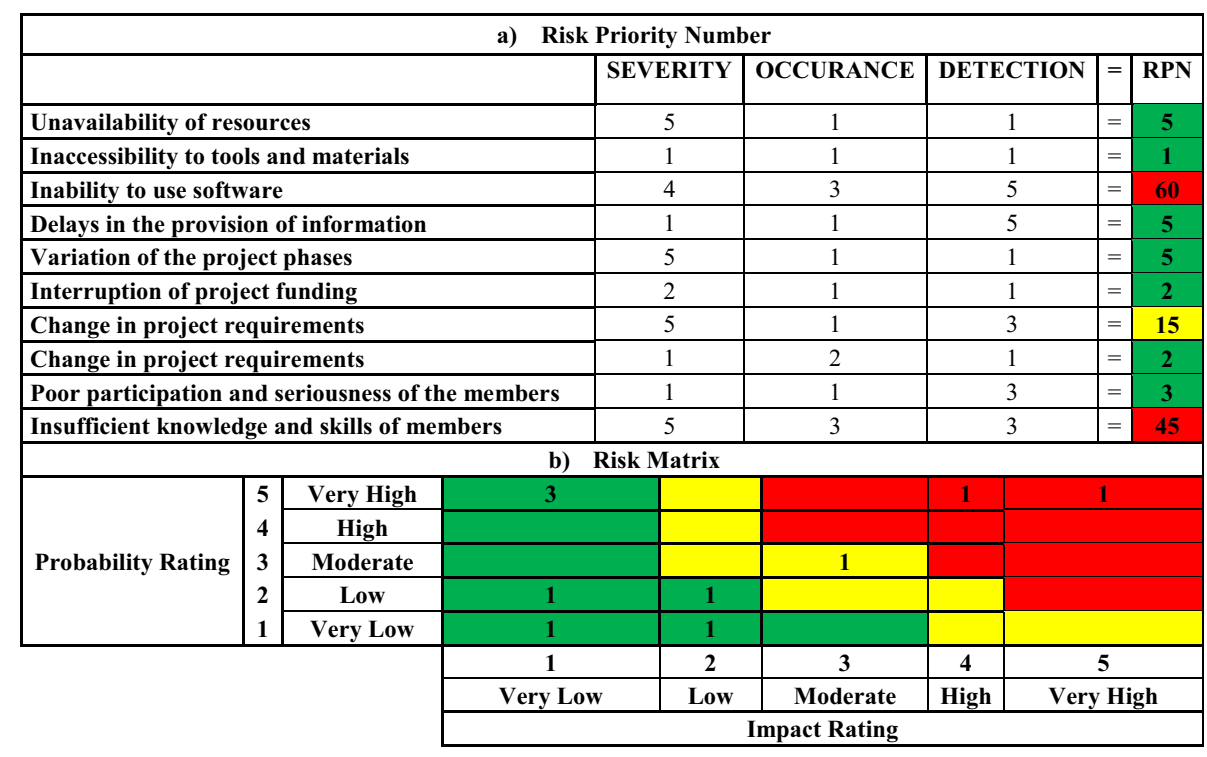




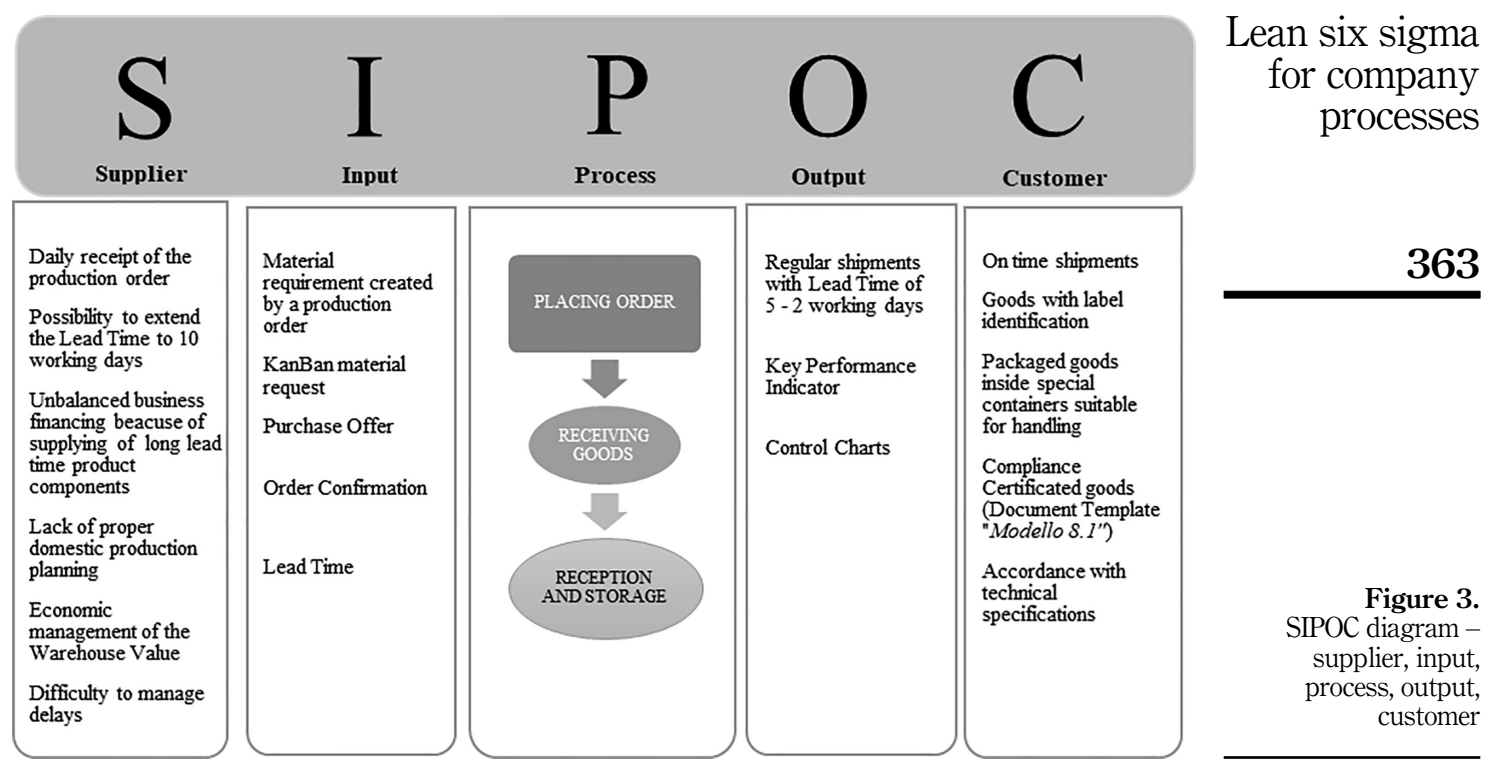

divided into $11.40417 \mathrm{~h}(11 \mathrm{~h} 24 \mathrm{~min}$ and $15 \mathrm{~s})$ for value-added activities and $2.216 \mathrm{~h}(12 \mathrm{~min}$ and $57 \mathrm{~s})$ for non-value-added activities. Together with downtime and shipping times, the entire process is performed with a maximum total Lead Time (L/T) of 8 days, 8 h, 5 min and $28 \mathrm{~s}$.

4.2.2.1 Data collection. Through the support of the company management software, for the period considered, the extrapolation of all the production components purchased from the supplier under study was carried out. On the basis of the CTQs, defined by Schnell and included in the Project Charter document, all deliveries with a delivery lead time of less than or equal to 5 working days have been marked as "Centered", while those with delivery lead times greater than 5 working days, have been signed as "Delay". The phenomenon under study is made up of a population of data with a number equal to $N=74$, characterized by the following 9 modes (see Figure 6):

(1) PRODUCT A.1;

(2) PRODUCT A.2;

(3) PRODUCT B.1;

(4) PRODUCT B.2;

(5) PRODUCT C.1;

(6) PRODUCT C.2;

(7) PRODUCT D.

These products are characterized by belonging to similar categories, therefore, with the aim of greater interpretation and a better comparison of data, the population has been grouped into stratified categories with reference to the product group to which they belong, type of production component and final product.

4.2.2.2 Interpretation of data with statistical tools. In the first phase, the graphical summary analysis was performed (Figure 6) showing the results of the Anderson-Darling Normality Test, the descriptive statistics and the confidence intervals for the mean, median 
TQM

33,7

\section{4}

Figure 4.

Flow Chart: Diagram of the procurement process through the Kanban system

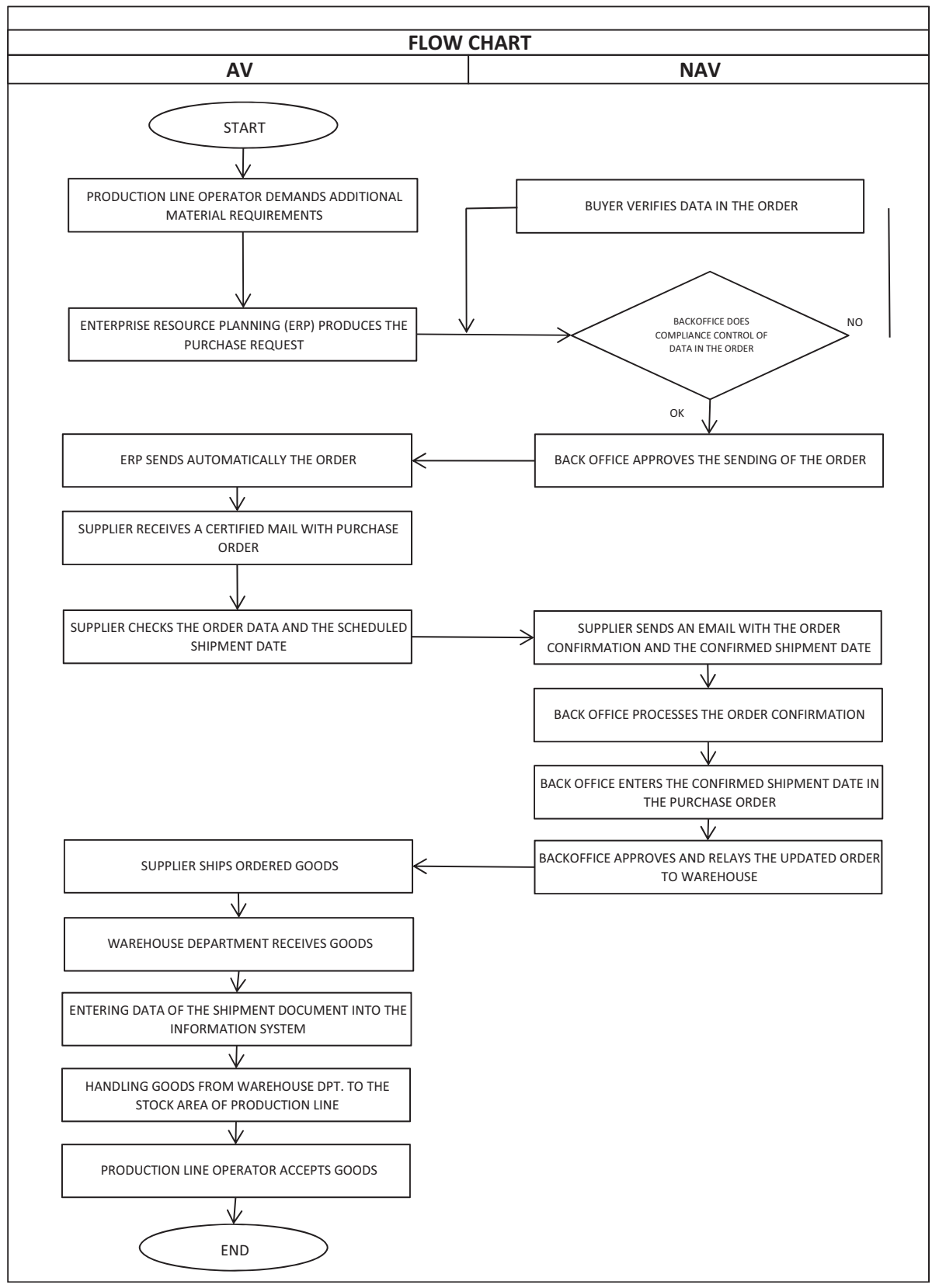

and standard deviation of the data population in exam. The graphs show that deliveries are characterized by an average delivery lead time of 9.4324 working days which falls within a range of 70 working days. The recorded variation therefore determines a standard deviation of 14.4877 . 
Lean six sigma

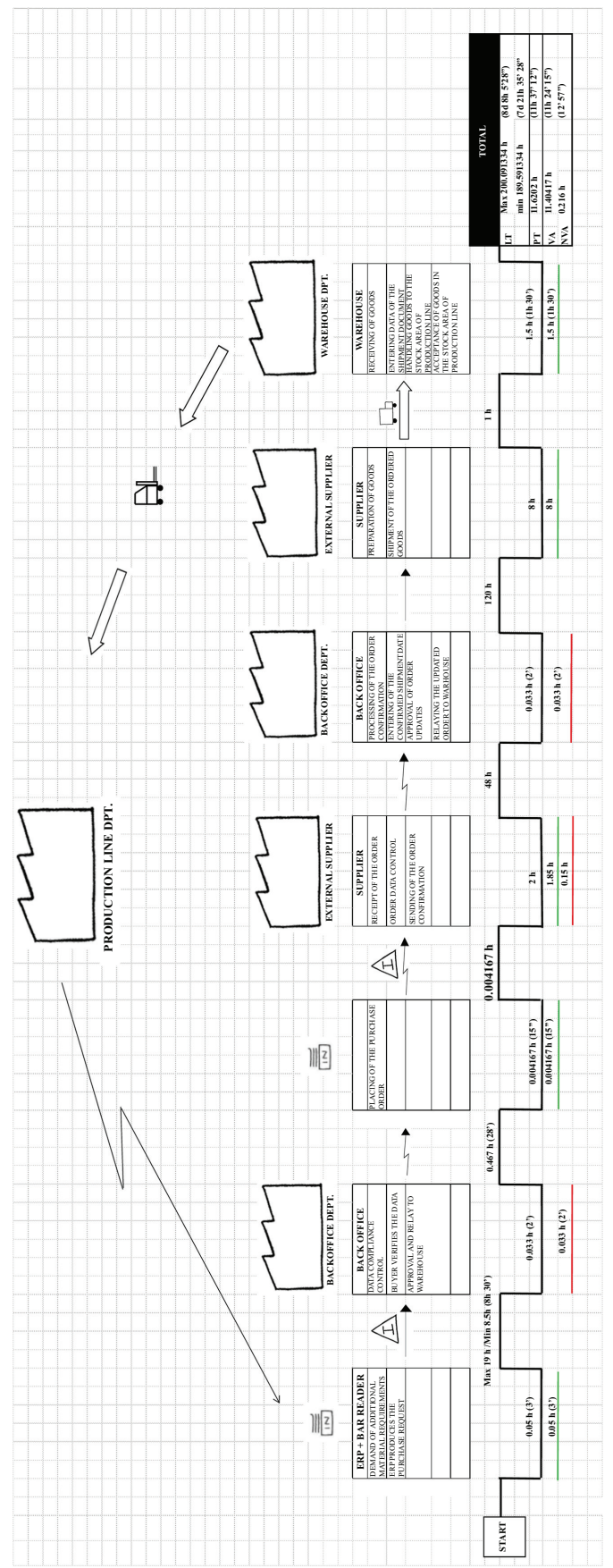

for company

processes

365

Figure 5.

Value stream mapping of the procurement process of the In-Lining line with Kanban system 


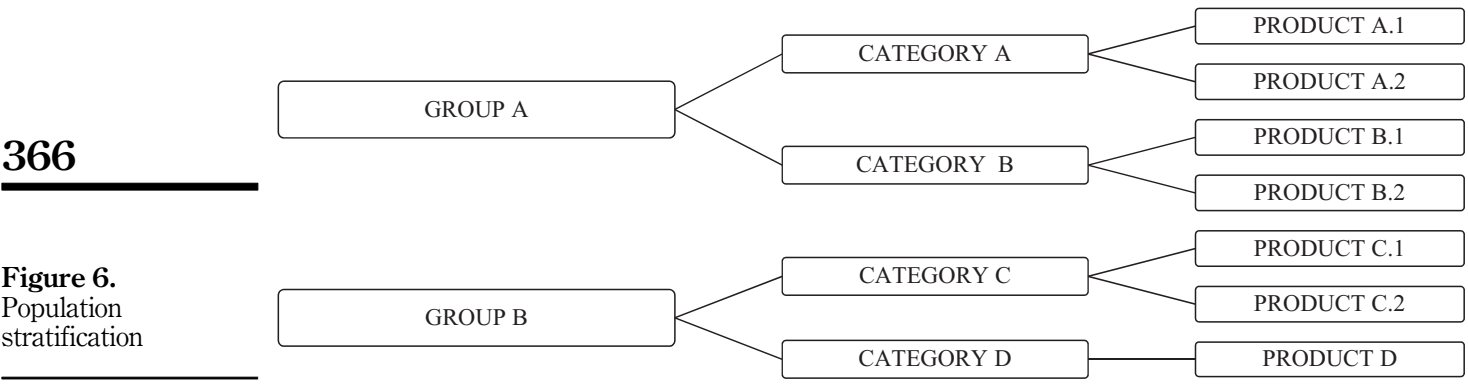

Second, from the Anderson-Darling normality test, a $p$-value $<0.005$ is obtained: this value demonstrates that the analyzed data derive from a distribution that cannot be approximated to a Gaussian model.

The current result is a consequence of the fact that in the population, in correspondence with the value in the 3rd Quartile of 7 days and Maximum of 74 working days, irregular values can be highlighted, called outliers, which arise from particular causes of a special type, and which therefore prevent a regular data analysis and interpretation, negatively affecting all study results.

It was highlighted that these were four deliveries relating to the same order, made on August 31, 2018, of two components of CATEGORY C, in particular of PRODUCT C.2.

Through a more in-depth investigation, it was possible to observe that the supply agreement was drawn up and confirmed prior to the first delivery of the product in the sample phase. Consequently, the high delivery lead time was justified by the fact that the supplier had to provide totally new products, the production of which had to be studied and adapted to their production processes.

Given the particular situation, to carry out a more meaningful analysis, it was decided not to consider the indicated outliers values, and to run the graphical summary analysis again, this time on a population made up of $N=70$ units (Figure 7).

In this case, the standard deviation assumes the value 4.1852 , the average delivery Lead Time tends to reduce to the value of 6.1429 working days; however, again it is possible to deduce a $p$-value $<0.005$; therefore, the data derives from a distribution that cannot be approximated to a Gaussian model. It is possible to conclude that the entire process is not under statistical control: the distribution consists of values that cannot be approximated to a Gaussian model, characterized by a supply trend that cannot be predicted over time.

On the basis of these results, it was possible to state that the supplier encountered numerous difficulties in fulfilling supply orders from the In-Lining Line, since the delivery process of the components was characterized by Lead Times that deviate significantly compared to the average lead time recorded (see Figure 8).

To express the supplier's performance in terms of Process Sigma, the values of Table 4 were taken into consideration, which summarizes the variables necessary for the calculation of the Defects Per Units (DPU), the Defects Per Opportunity (DPO) and the Defects per Million of opportunity (DPMO) index:

$$
\mathrm{DPU}=\frac{\text { Numerosità difetti rilevata }(D)}{\text { Numerosità campione }(U)}
$$




\section{Summary Report for LEAD TIME SHIPMENT}

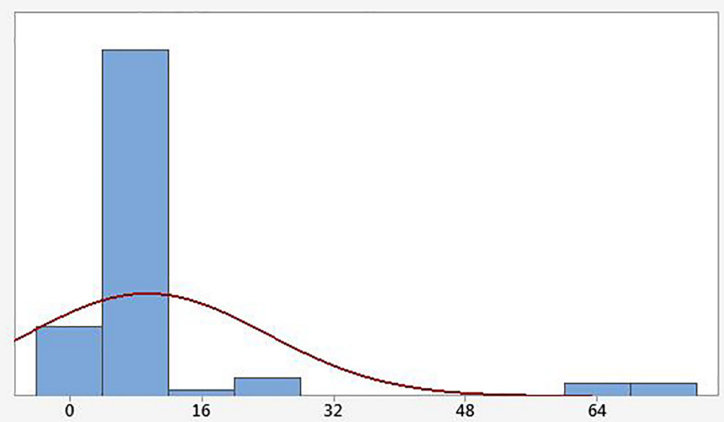

(a)

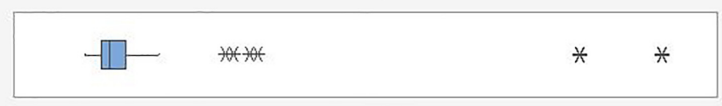

(b)

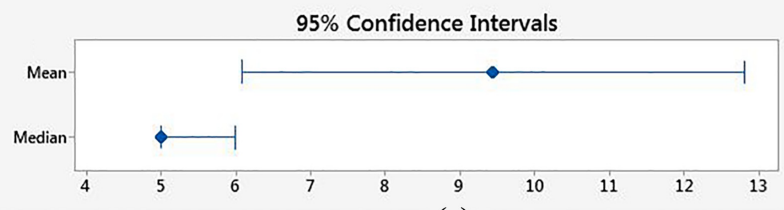

(c)

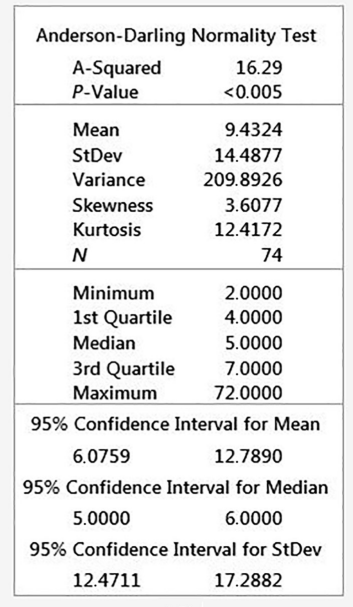

(d)
Lean six sigma for company processes

367

$$
\begin{gathered}
\mathrm{DPO}=\frac{\mathrm{DPU}}{\text { Opportunità di errore }(O)} \\
\mathrm{DPMO}=\mathrm{DPO} \times 1.000 .000
\end{gathered}
$$

The supply of the In-Lining line is characterized by a Sigma Level equal to 1.85, therefore, the current process is carried out with a yield of $63.51 \%$.

4.2.3 "Analyze" phase. Based on the considerations obtained from the measurements made in the Measure phase, in this third stage of the project the team's goal was to intercept the categories of components that found the greatest difficulties in the procurement process.

Considering the high variability of the delivery process, in order to identify priority areas of intervention, the analysis was further processed through the Pareto diagram and, for easier interpretation, it was carried out by stratifying the data on the basis of the single category of belonging (see Figures 9 and 10).

It was observed that $39 \%$ of deliveries (Table 5), carried out in the period under consideration, were carried out outside the established lead time specifications of 5 working days. The supplier presents the greatest number of critical issues with the fulfillment of orders relating to the GROUP A category, in particular with the fulfillment of PRODUCT A.1 and PRODUCT A.2, and to a lesser extent, with PRODUCT B.1 and PRODUCT B.2.

For the GROUP B category, difficulties were found in the delivery of the PRODUCT C.2 and PRODUCT D components; however, for the latter, the non-conformities found cannot be analyzed, as they are insignificant.

4.2.4 "Improve" phase. In the Improve phase, the purpose of the study activity was to identify the root causes of the problems that the Business Partner identified in the process of 


\section{TQM}

33,7

\section{8}

Figure 8.

Graphical summary statistical analysis of Lead Times recorded in the period 01/01/201831/10/2019. Population with numbers $N=70$

\section{Summary Report for LEAD TIME SHIPMENT}

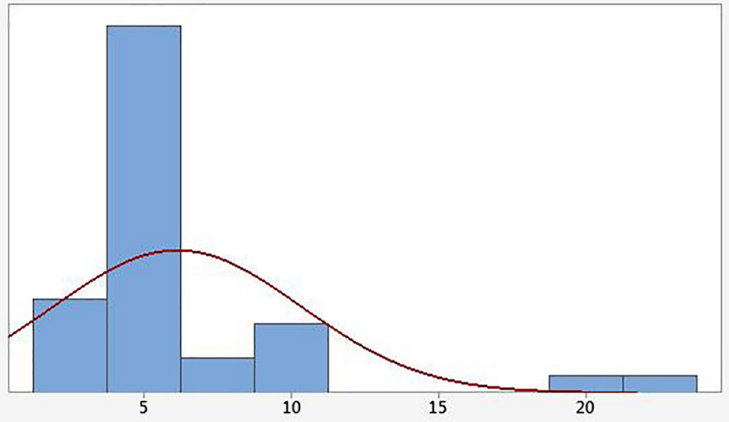

(a)

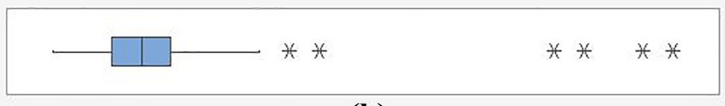

(b)

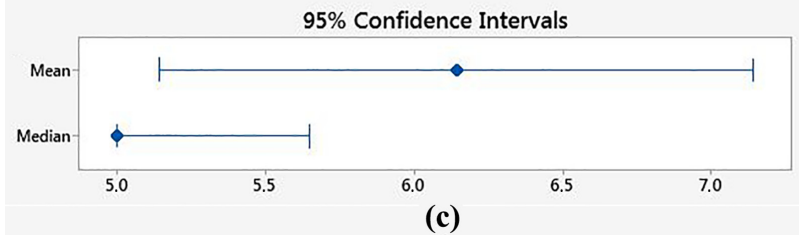

\begin{tabular}{|cc|}
\hline \multicolumn{3}{|c|}{ Anderson-Darling } & Normality Test \\
A-Squared & 7.18 \\
P-Value & $<0.005$ \\
\hline Mean & 6.1429 \\
StDev & 4.1852 \\
Variance & 17.5155 \\
Skewness & 2.69171 \\
Kurtosis & 7.76570 \\
N & 70 \\
\hline Minimum & 2.0000 \\
1st Quartile & 4.0000 \\
Median & 5.0000 \\
3rd Quartile & 6.0000 \\
Maximum & 23.0000 \\
\hline 95\% Confidence Interval for Mean \\
5.1449 & 7.1408 \\
95\% Confidence Interval for Median \\
5.0000 & 5.6483 \\
95\% Confidence Interval for StDev \\
3.5884 & 5.0218 \\
\hline
\end{tabular}

(d)
Calculation of the sigma process (DPMO method)

Opportunities of defects $(\mathrm{O})$

Sample size (U)

Number of defects (D)

DPU (defects per unit)

DPMO (defects per million of opportunity)

Table 4.

Process sigma

Yield

364.86486

Process sigma

fulfilling the supply orders of the In-Lining line, and secondly to identify the paths for improvement to correct the criticalities detected.

4.2.4.1 Root cause analysis. The study was developed by analyzing the temporal trend of orders in the period considered for each PRODUCT category indicated at the end of the Analyze phase. For deliveries with greater difficulty, inquiries were carried out on the dates of issue and actual delivery of supply orders. In this phase, the help offered by the Production Planner of the Production Department who deals with the management of the production planning of the In-Lining cell was of great support. First of all, it was possible to deepen that in the delivery process of PRODUCT A.1 and PRODUCT C.2, in relation to the deliveries of the orders of the week 3/2019 and 2/2019, issued respectively with Lead Time of 23 and 22 working days, the supplier communicated the breakdown of a machinery necessary for the production of the components; therefore, it was not able to respect the contractual 


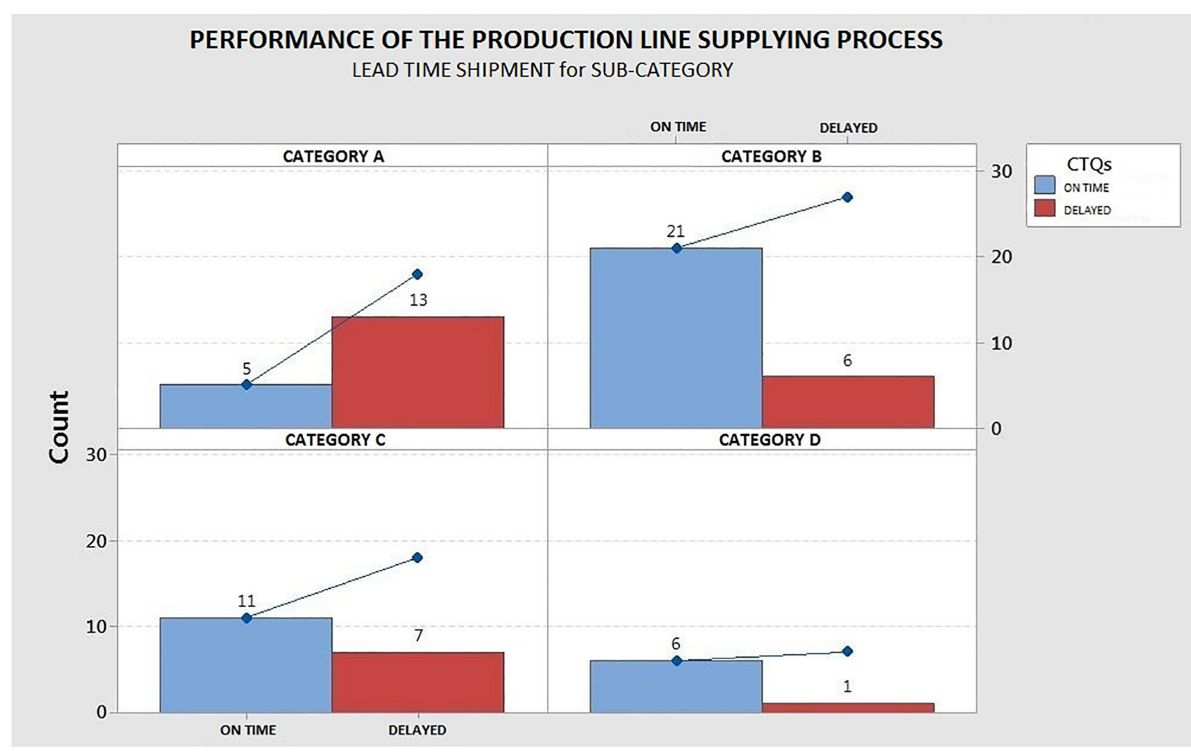

Lean six sigma for company processes

(a)

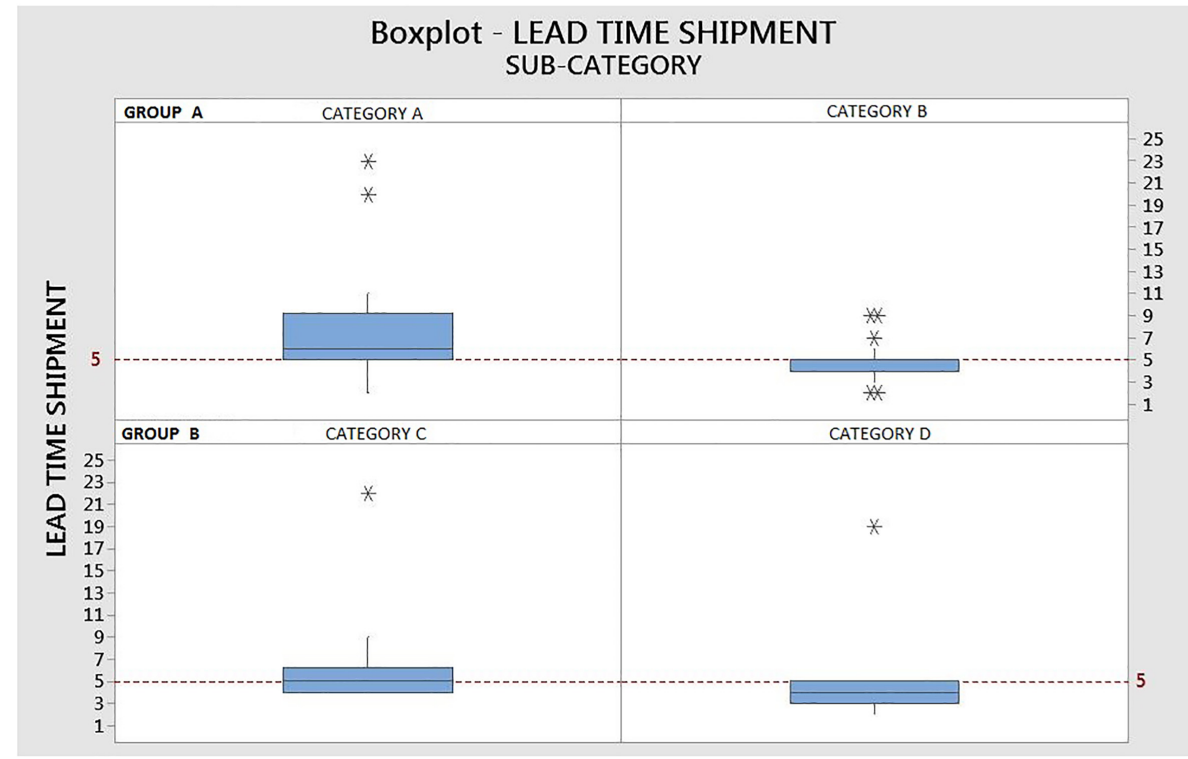

(b)

specifications. The Lead Time values detected here can be considered as outliers, determined by causes of a special type.

By analyzing PRODUCT A.2, it was possible to ascertain that some phases of the production process of the supplier in question were carried out in outsourcing to external suppliers not regulated by subcontracting contracts and, therefore, without evaluations in 
TQM

33,7

370

Figure 10.

Frequency of deliveries with centered and delayed lead time (a) and boxplot lead time (b) for subcategory type

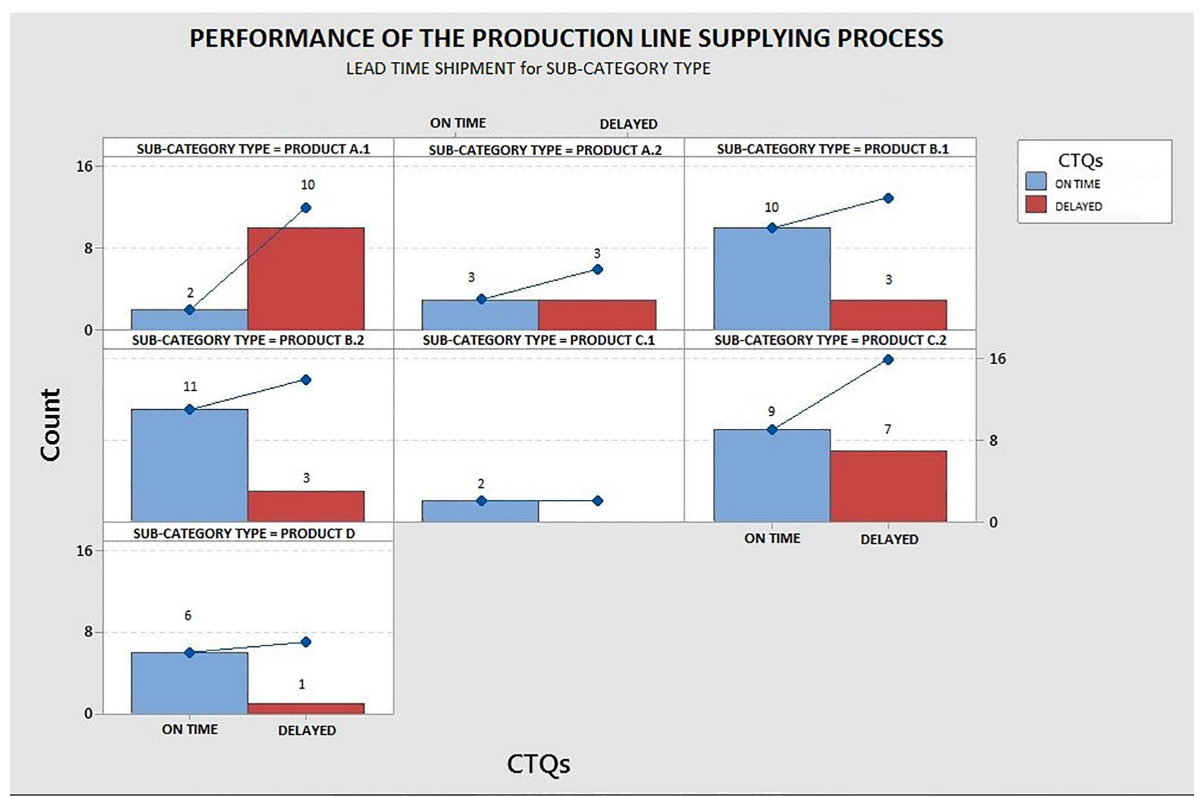

(a)

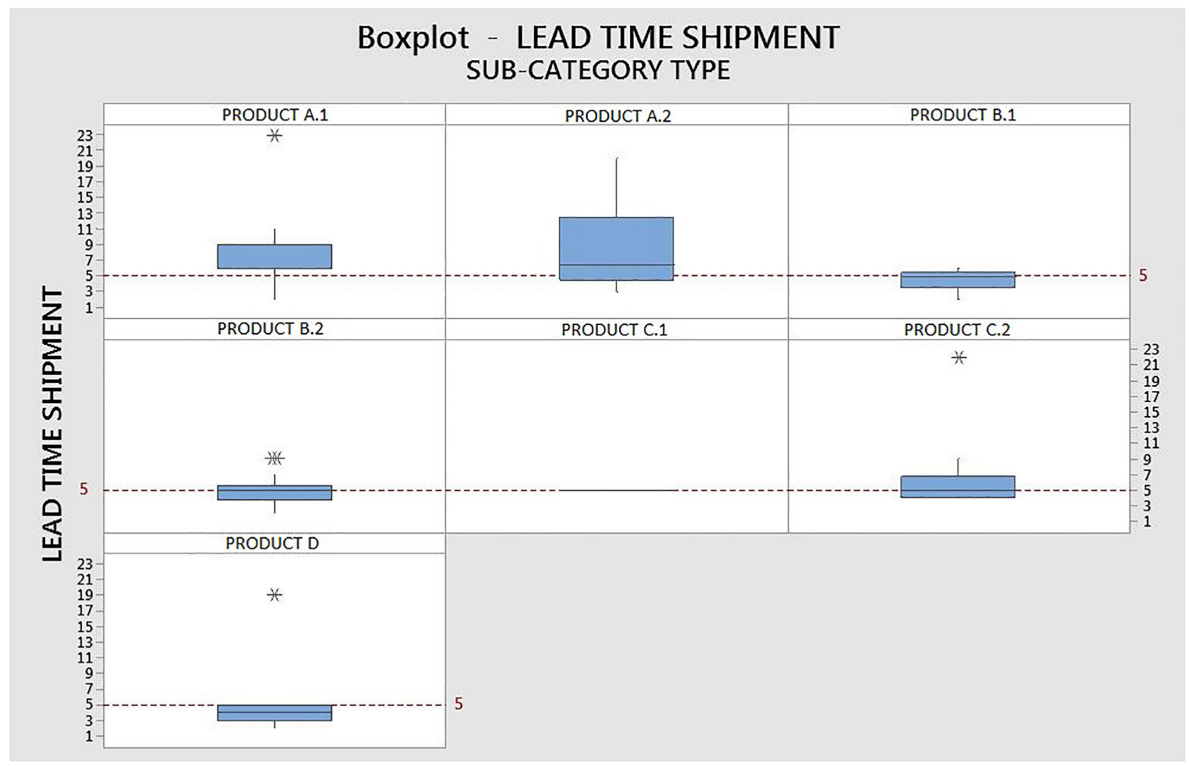

(b)

terms of lead time. As a result of this type of production management, instabilities in the internal delivery process have been generated. 


\begin{tabular}{|c|c|c|c|c|c|c|c|c|}
\hline \multirow{3}{*}{$\begin{array}{l}\text { Total } \\
\text { deliveries }\end{array}$} & & Deliv & Novembe & \multicolumn{2}{|c|}{$\begin{array}{l}\text { Percentage } \\
\text { frequency }\end{array}$} & \multicolumn{2}{|c|}{$\begin{array}{l}\text { Cumulative } \\
\text { frequency }\end{array}$} & \multirow[t]{3}{*}{$\begin{array}{r}\text { Lean six sigma } \\
\text { for company } \\
\text { processes }\end{array}$} \\
\hline & $\begin{array}{c}\text { Total } \\
\text { shipments }\end{array}$ & $\begin{array}{l}\text { CTQ on } \\
\text { time }\end{array}$ & $\begin{array}{l}\text { CTQ } \\
\text { delayed }\end{array}$ & $\begin{array}{l}\text { On } \\
\text { time }\end{array}$ & Delayed & $\begin{array}{l}\text { On } \\
\text { time }\end{array}$ & Delayed & \\
\hline & 70 & 43 & 27 & $61 \%$ & $39 \%$ & & & \\
\hline Category & & & & & & & & \\
\hline GROUP a & 45 & 26 & 19 & $37 \%$ & $27 \%$ & $58 \%$ & $42 \%$ & \\
\hline GROUP B & 25 & 17 & 8 & $24 \%$ & $11 \%$ & $68 \%$ & $32 \%$ & \\
\hline Sub-category & & & & & & & & \\
\hline CATEGORY a & 18 & 5 & 13 & $7 \%$ & $19 \%$ & $28 \%$ & $72 \%$ & \\
\hline CATEGORY B & 27 & 21 & 6 & $30 \%$ & $9 \%$ & $78 \%$ & $22 \%$ & \\
\hline CATEGORY C & 18 & 11 & 7 & $16 \%$ & $10 \%$ & $61 \%$ & $39 \%$ & \\
\hline CATEGORY D & 7 & 6 & 1 & $9 \%$ & $1 \%$ & $86 \%$ & $14 \%$ & \\
\hline Sub-category-ype & & & & & & & & \\
\hline PRODUCT A.1 & 12 & 2 & 10 & $3 \%$ & $14 \%$ & $17 \%$ & $83 \%$ & \\
\hline PRODUCT A.2 & 6 & 3 & 3 & $4 \%$ & $4 \%$ & $50 \%$ & $50 \%$ & \\
\hline PRODUCT B.1 & 13 & 10 & 3 & $14 \%$ & $4 \%$ & $77 \%$ & $23 \%$ & Table 5. \\
\hline PRODUCT B. 2 & 14 & 11 & 3 & $16 \%$ & $4 \%$ & $79 \%$ & $21 \%$ & Report of the \\
\hline PRODUCT C.1 & 2 & 2 & 0 & $3 \%$ & $0 \%$ & $100 \%$ & $0 \%$ & performances analyzed \\
\hline PRODUCT C.2 & 16 & 9 & 7 & $13 \%$ & $10 \%$ & $56 \%$ & $44 \%$ & in the period November \\
\hline PRODUCT D & 7 & 6 & 1 & $9 \%$ & $1 \%$ & $86 \%$ & $14 \%$ & 2018-October 2019 \\
\hline
\end{tabular}

Considering the exceptions found for the cases described above, with reference to all the components observed, therefore to PRODUCT A.1, PRODUCT A.2, PRODUCT B.1, PRODUCT B.2 and PRODUCT C.2, the analysis carried out allowed to note that:

(1) For some deliveries, the supply lead time has been calculated incorrectly.

(2) The supplier tends not to comply with lead time specifications, especially after prolonged company closure periods and in correspondence with orders processed in short periods.

To identify the root cause of the difficulties highlighted, the Five Why (5Why) method was used, which allowed to identify the cause-and-effect relationships of the problems to be analyzed (Table 6). With the help of this problem finding tool, it was possible to ascertain that for some deliveries examined, the delivery lead time was calculated incorrectly as for orders corresponding to the deliveries themselves, the generation date did not correspond to the date of sending the order to the supplier. The system for sending supply orders for the In-Lining line provides that the verification and approval phase, carried out after the automatic proposal generation phase, takes place manually through the action of the Back Office Purchase Department operator. In situations of absence of the operator, or late approval of the order, the supplier receives the document on a different date from that of issue.

With reference to the second problem identified, it was analyzed that the Business Partner highlights critical issues in terms of supply lead time, in relation to the fulfillment of orders received following prolonged company closure periods and for those received in short periods.

In the first case, these are deliveries made in the time interval corresponding to the periods of early January, late April and early September: time intervals that follow the periods of company holidays for national holidays.

It was assumed that prior to these company holiday periods, the warehouse safety stock was entirely consumed and not restored with further production of components. Therefore, it 


\begin{tabular}{l} 
TQM \\
33,7 \\
$\mathbf{3 7 2}$ \\
\hline
\end{tabular}

Table 6.

Five why matrix
복

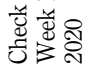

范亏

苞裘

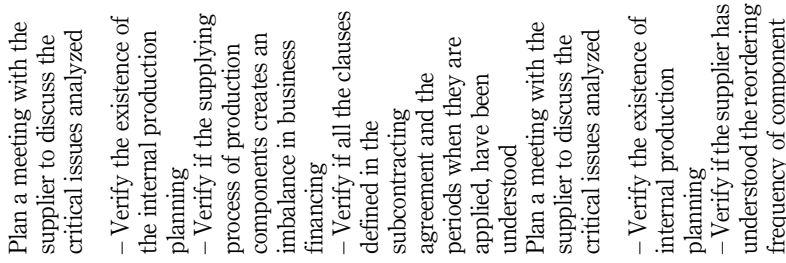

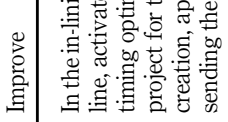

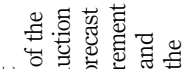

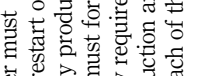

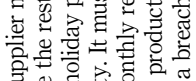

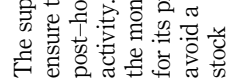

题

政

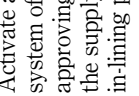

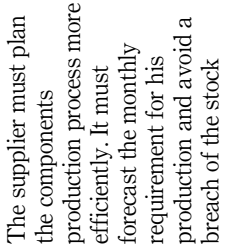

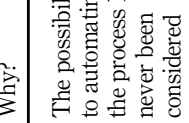

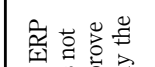

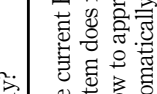

管

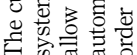

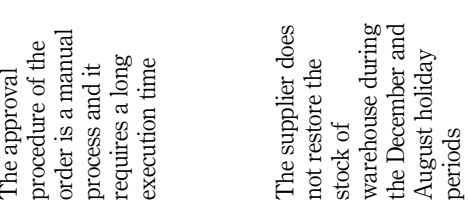

है

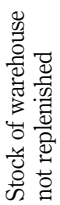

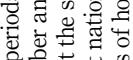

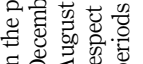

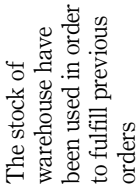

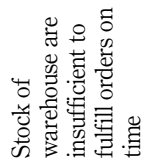

范。苛

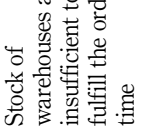

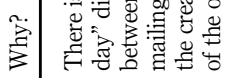

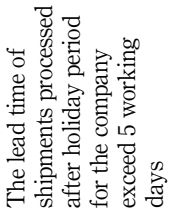

范

家

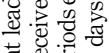

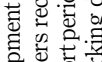

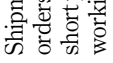

占占氮蒙 
was considered that the supplier finds it difficult to ensure the restart of the post-holiday production activity through the forecast of its monthly requirements; therefore, it is unable to prevent the stock breaking of its warehouse.

For the second case, however, the supplier presented difficulties in fulfilling the orders placed in correspondence of short periods. More precisely, an out of specification Lead Time was highlighted in correspondence with the second/third order received in a monthly time interval. Also, for this criticality it has been hypothesized that there may be difficulties in ensuring an efficient planning of production activities and a correct forecast of one's monthly requirements, without incurring stock-outs in one's warehouse.

Having carefully analyzed all the factors resulting from the study carried out and in relation to the root causes detected, in order to stabilize the supply process of the In-Lining line, the following solutions were indicated:

(1) Activate an automatic system for generating, approving and sending orders to the supplier;

(2) Arrange a meeting with the business partner in order to discuss the critical issues detected in the period studied.

With the aim of preventing further errors in the measurement system of the supply lead time indicator, and therefore overcoming the time gaps recorded between the generation phase and the order sending phase, the information technology (IT) department was entrusted with the task to generate an IT system that can automatically complete the entire process of fulfilling the supply orders coming from the In-Lining line. Considering the utmost importance of this improvement activity, the automatism created was implemented in the process starting from the first week of February 2020.

Considering the second improvement activity, the team evaluated the opportunity to organize a meeting with the Business Partner in order to discuss the various difficulties identified by the study carried out. In particular, the analysis of the following critical points was envisaged:

(1) Check the efficiency of internal production planning;

(2) Verify whether the process of managing the economic lot and purchasing the components creates an imbalance in the company loan;

(3) Check if all the clauses contained in the stipulated subcontracting contract have been effectively understood;

(4) Check if in the production planning phase, the periodicity of reordering of components is taken into consideration.

Lastly, having ascertained the delivery problems encountered when supplying the PRODUCT A.2 component, the Management of the production process of the In-Lining line carried out a strategic Make or Buy analysis. As a result of the evaluation carried out, on $14 / 11 / 2019$, the subcontracting contract was canceled and the procurement of the components was entrusted to an alternative Business Partner.

4.2.5 "Control" phase. In the last phase of the DMAIC project, some activities were identified and implemented in order to keep under control the improvement activities introduced in the Improve phase.

To verify the operation and validity of the automated system for generating, approving and sending the supply orders of the In-Lining line, the IT department has launched a checkup mechanism with the aim of transmitting to the Purchase Department a daily report on the effective sending of orders created automatically. 
TQM

33,7
Considering, however, the need to investigate the possible difficulties encountered, the meeting with the Business Partner was scheduled for the second week of March.

\subsection{Benefits deriving from the implementation of the project}

After an accurate analysis of the problem related to the reduction of lead time and its causes, it has emerged that the main concern is that in most cases the supply lead time has been calculated incorrectly, while in others supplier tends not to comply with lead time specifications, mostly after company closure periods and when orders are processed in short periods.

First, the implementation of the project has made the company become fully aware of the inefficiencies present in the delivery process of some of its components, allowing a high reduction in the variability of the external production process of these components. Reducing delivery times has also allowed to better plan the supply of production components, defining the periods for sending purchase orders. An automatic system for managing supplier orders has been activated, and it has permitted to reduce errors during the order creation and management process, having a positive effect on the consolidation of the process under consideration. Moreover, a meeting with suppliers was carried out and it has permitted to discuss and confirm together with the business partners the clauses contained in the subcontracting contract, to better plan the periodicity of reordering of components, but also internally improve the efficiency of production planning. From a quantitative point of view, the benefits will be assessed over the long term, with a careful analysis.

\section{Conclusion, implications and future research directions}

This study was carried out with the main objective of describing the path and dynamics of the transformation process that business organizations undertake with the aim of optimizing their profitability and competitive advantage following the profound environmental changes to which they are subject to, placing emphasis on an innovative methodology for conducting business process improvement projects, known as Lean Six Sigma, which constitutes its operating philosophy on the effective and efficient use of company resources and skills, to guarantee to the company the achievement of a lasting and defensible competitive advantage over time. Lean Six Sigma has been presented in this research as a methodology for improving business productivity, which operates through the reduction of the constraints and inefficiencies of each production and transactional process, aspiring to the maximum satisfaction of the internal and external customer and is configured as a real strategy, which offers to the human resources an innovative way of thinking and working based on training growth, data culture and the use of problem-solving methodologies that allow the improvement of quality, the reduction of costs and company complexities. In this detailed case study, the DMAIC technique was applied in a project to stabilize the procurement process of a pull-type production cell, which experienced some problems in terms of delays in supply lead times.

Thanks to the analyses carried out and the results obtained with the processing of the DMAIC phases, it was possible to highlight the potential causes of the problems that the business partner could have presented in their process of managing the supply of the production cell. Furthermore, some inefficiencies in the internal process of fulfillment of supply orders have been intercepted, the optimization of which has allowed the generation of an automatic system for sending supply orders, coming directly from the production line; a small tweak that will undoubtedly have a positive effect on the consolidation of the process under consideration, as the purchase department will be able to both keep order fulfillment under control and develop a more efficient measurement of business partner performance indicators.

With the development of the project, it was possible to structure the initial guidelines for the subsequent in-depth analysis of the critical issues identified. In particular, for the stabilization of the entire process, Schnell S.p.A. will have to develop an intense relationship 
of collaboration and mutual growth with his supplier to identify and implement the best solutions to the variability of the supply order fulfillment process.

The practical implementation of the Lean Six Sigma project confirmed the validity and power of the principles professed by this improvement methodology: the importance of customer orientation and the elimination of waste of resources; the value of a work team and the continuous search for qualitative and quantitative data that support and facilitate the decisions of each member of the group.

It was particularly fruitful to discover how collaboration and involvement within an LSS working group amplifies the skills and knowledge of each participant and generates a widespread climate of enthusiasm and strong determination for continuous improvement in every area, both at work and personal level.

Another practical implication that emerged from the study was the high importance to be attributed to the process of measuring company performance. From a consistent database and their level of reliability, it is possible to identify important opportunities for improvement and savings in terms of company resources; the data make it possible to highlight significant problems and inefficiencies, otherwise not recognizable, which are the result of high company costs that impact on company profitability.

The research shows how Lean Six Sigma can offer companies high advantages in achieving the highest quality in the value creation process, however, to ensure the successful success of projects, the desire for change must arise from the depths of top management; it will have to assume the role of promoter of the LSS culture and philosophy, so that the tools of the methodology are effective in managing and guiding the improvement and transformation actions, one step at a time, with rigor and discipline, but with the involvement of all own resources, with the greatest possible efficiency and effectiveness.

The main limitation of the study derives from the qualitative methodology adopted, that while it permits to analyze in depth and broadly all the phases of implementation of the LSS in the company, highlighting the difficulties encountered during the activities and the benefits obtained, these results should be integrated with an analysis on a large sample of companies that have developed similar projects to be more generalizable. Future research should be oriented on developing a quantitative analysis on LSS implementation. In any case, a qualitative study of this depth can give ideas for improvement and development for companies similar in structure and dimension to Schnell S.p.A.

\section{References}

Albliwi, S.A., Antony, J. and halim Lim, S.A. (2015), "A systematic review of Lean Six Sigma for the manufacturing industry”, Business Process Management Journal, Vol. 21 No. 3, pp. 665-691, doi: 10.1108/BPMJ-03-2014-0019.

Antony, J., Snee, R. and Hoerl, R. (2017), "Lean Six Sigma: yesterday, today and tomorrow", International Journal of Quality and Reliability Management, Vol. 34 No. 7, pp. 1073-1093.

Bhat, S., Gijo, E.V., Rego, A.M. and Bhat, V.S. (2020), "Lean Six Sigma competitiveness for micro, small and medium enterprises (MSME): an action research in the Indian context", The TQM Journal, Vol. 33 No. 2, pp. 379-406, doi: 10.1108/TQM-04-2020-0079.

Chiarini, A. (2012), Lean Organization: From the Tools of the Toyota Production System to Lean Office, Vol. 3 Springer Science \& Business Media.

Corbett, L.M. (2011), "Lean Six Sigma: the contribution to business excellence", International Journal of Lean Six Sigma, Vol. 2 No. 2, pp. 118-131, doi: 10.1108/20401461111135019.

Cudney, E., Elrod, C. and Stanley, S. (2014), "A systematic literature review of Six Sigma practices in education", International Journal of Six Sigma and Competitive Advantage, Vol. 8 Nos 3/4, pp. 163-175.

Lean six sigma for company processes 
TQM 33,7

Galdino de Freitas, J. and Gomes Costa, H. (2017), "Impacts of Lean Six Sigma over organizational sustainability. A systematic literature review on Scopus base", International Journal of Lean Six Sigma, Vol. 8 No. 1, pp. 89-108.

Gijo, E.V., Jiju, A. and Vijaya, S.M. (2019), "Application of Lean Six Sigma in IT support services - a case study", The TQM Journal, Vol. 31 No. 3, pp. 417-435.

Hoerl, R.W. and Gardner, M.M. (2010), "Lean six sigma, creativity, and innovation", International Journal of Lean Six, Sigma, Vol. 1 No. 1, pp. 30-38.

Jayaram, A. (2016), "Lean six sigma approach for global supply chain management using industry 4.0 and IIoT", Conference: 2016 2nd International Conference on Contemporary Computing and Informatics (IC3I), pp. 89-94.

Lande, M., Shrivasatava, R.L. and Seth, D. (2016), "Critical success factors for Lean Six Sigma in SMEs (small and medium enterprises)", The TQM Journal, Vol. 28 No. 4, pp. 613-635.

Laureani, A. and Antony, J. (2012), "Standards for lean six sigma certification”, International Journal of Productivity and Performance Management, Vol. 61 No. 1, pp. 110-120.

Pepper, M.P.J. and Spedding, T.A. (2010), "The evolution of lean Six Sigma”, International Journal of Quality and Reliability Management, Vol. 27 No. 2, pp. 138-155.

Raval, S.J., Kant, R. and Shankar, R. (2018), "Lean Six Sigma implementation: modelling the interaction among the enablers", Production Planning and Control, Vol. 29 No. 12, pp. 1010-1029.

Shah, R., Chandrasekaran, A. and Linderman, K. (2008), "In pursuit of implementation patterns: the context of Lean and Six Sigma”, International Journal of Production Research, Vol. 46 No. 23, pp. 6679-6699.

Singh, M. and Rathi, R. (2019), "A structured review of Lean Six Sigma in various industrial sectors", International Journal of Lean Six Sigma, Vol. 10 No. 2, pp. 622-664.

Singh, M., Kumar, P. and Rathi, R. (2019), "Modelling the barriers of Lean Six Sigma for Indian micro-small medium enterprises. An ISM and MICMAC approach", The TQM Journal, Vol. 31 No. 5, pp. 673-695.

Snee, R.D. (2010), "Lean Six Sigma-getting better all the time", International Journal of Lean Six Sigma, Vol. 1 No. 1, pp. 9-29.

Snee, R.D. and Hoerl, R.D. (2007), "Integrating lean and Six Sigma: a holistic approach", Six Sigma Forum Magazine, Vol. 6 No. 3, pp. 15-21.

Sordan, J.E., Optime, P.C., Pimenta, M.L., Chiabert, P. and Lombardi, F. (2020), "Lean Six Sigma in manufacturing process: a bibliometric study and research agenda”, The TQM Journal, Vol. 32 No. 3, pp. 381-399.

Sreedharan, V.R. and Raju, R. (2016), "A systematic literature review of Lean Six Sigma in different industries”, International Journal of Lean Six Sigma, Vol. 7 No. 4, pp. 430-466, doi: 10.1108/ IJLSS-12-2015-0050.

Sunder, M.V. and Antony, J. (2018), "A conceptual Lean Six Sigma framework for quality excellence in higher education institutions", International Journal of Quality and Reliability Management, Vol. 35 No. 4, pp. 857-874.

Timans, W., Antony, J., Ahaus, K. and Solingen, R. (2012), "Implementation of Lean Six Sigma in small and medium-sized manufacturing enterprises in The Netherlands", Journal of Operational Research Society, Vol. 63 No. 3, pp. 339-353.

Yin, R.K. (1994), Case Study Research: design and Methods, 2nd ed., Sage Publishing, Thousand Oaks, CA.

\section{Corresponding author}

Laura Bravi can be contacted at: laura.bravi@uniurb.it

For instructions on how to order reprints of this article, please visit our website:

www.emeraldgrouppublishing.com/licensing/reprints.htm

Or contact us for further details: permissions@emeraldinsight.com 